\title{
Molecular Dynamics Simulation of Cetyl Phosphate Adsorption in Flotation of Magnesite and Pertinent Chemical Aspects
}

\author{
Yuan Tang ${ }^{1,2}{ }^{\oplus}$, Jin Yao ${ }^{1, *}$, Wanzhong Yin ${ }^{1}$ and Sadan Kelebek ${ }^{2, *}$ \\ 1 School of Resources and Civil Engineering, Northeastern University, Shenyang 110819, China; \\ yuan.tang@queensu.ca (Y.T.); luckyt_neu@163.com (W.Y.) \\ 2 The Robert M. Buchan Department of Mining, Queen's University, Kingston, ON K7L 3N6, Canada \\ * Correspondence: crushty@163.com (J.Y.); sadan.kelebek@queensu.ca (S.K.); Tel.: +1-613-533-2230 (S.K.)
}

Received: 10 August 2020; Accepted: 26 August 2020; Published: 27 August 2020

\begin{abstract}
Magnesite ores are important resources in the production of value-added magnesium materials. Generally, low selectivity of conventional collectors and the requirement of a large amount of depressant has been a motivation for researchers to identify alternate collectors. In this work, the role of potassium cetyl phosphate (PCP) as a new collector in magnesite flotation is investigated using molecular dynamics (MD) simulations and chemical equilibria, electrokinetics and wettability. The results indicate that PCP exhibits a strong collecting ability for magnesite particles even with low concentrations. The presence of PCP leads to significant alterations in the electric double layer and contact angle behavior of magnesite, which results in rapid adsorption of PCP on magnesite surface. The results from chemical computations show that the monoanionic forms of $\mathrm{PCP}$ are the dominant species in the weakly acidic $\mathrm{pH}$ range, where monohydroxy magnesium species and the ion concentration of magnesite in suspension can be controlled by adjusting $\mathrm{pH}$. The adsorption models indicate that the stable adsorption of PCP on magnesite surfaces occurs spontaneously, supporting the potentiality for selective magnesite flotation in its separation from other carbonate minerals.
\end{abstract}

Keywords: cetyl phosphate; magnesite; molecular dynamics simulation; solution chemistry; flotation

\section{Introduction}

The magnesium carbonate mineral, magnesite, is one of the most common salt-type minerals, which are characterized by their ionic bonding and are distinguished from soluble salt minerals by their limited solubility in water. From the geological perspective, however, magnesite in natural ore deposits is always associated with other minerals that represent gangue minerals [1]. The demand for the production of high-quality magnesite increased considerably in recent years, which made it necessary to develop efficient methods for magnesite separation from its associated minerals $[2,3]$.

Flotation is regarded as a major method used for the beneficiation of magnesite ores [4]. Traditional fatty acids and amines are typically reported as collectors in the industrial flotation of magnesite ores [5]. Beyond that, as the key factor of flotation, a series of novel cationic collectors have been reported for the flotation separation of the magnesite from associated silicates, and some of them have excellent separation results [6,7]. However, the clear-cut separation of magnesite from carbonate minerals is still a technical challenge [3]. The commonly used collectors show strong collecting ability for magnesite as well as other associated carbonate minerals due to the similarity of crystal structures and physicochemical characteristics of the mineral surfaces [8-10]. Consequently, there is a need that has been recognized among researchers to identify more selective collectors acting on such minerals. Some phosphorus-containing collectors exhibit improved response for many minerals, 
such as bastnaesite [11], cassiterite [12], and dolomite [13]. According to infrared spectra analyses, a phosphate group connected to a lauryl chain undergoes a complexation reaction with cations $[14,15]$. In addition, dodecyl phosphate, an effective collector for magnesite and dolomite, plays an active role in the flotation of carbonate minerals by chemical adsorption [16]. Studies have suggested that alkyl phosphates might be superior to conventional collectors in flotation $[3,11]$.

Molecular dynamics (MD) simulations have become an effective and important method for the investigation of the adsorption mechanism of surfactants at the liquid/solid interfaces [17,18]. Meanwhile, the interaction behavior and the dynamic characteristics of the adsorption process can be obtained [19]. Srinivas et al. discussed the formation of surfactant structures on a graphite surface with the different alkyl chain lengths, and their results showed that the shorter the alkyl chain length the easier it will be to form monolayers [20]. To achieve effective flotation, combined collectors have been used to exhibit enhanced recovery and selectivity for different minerals, and the mechanism of the enhancement was explained using molecular dynamics (MD) simulations [21]. For the phosphorus-containing anionic collectors, Liu et al. compared the adsorption states of branched-chain phosphate and lauryl phosphate on the bastnaesite surface. They found that lauryl phosphate showed a stronger flotation response due to a chemisorption when compared to 2-ethylhexyl phosphate [11]. To our knowledge, there have been only limited reports about the adsorption mechanism of the phosphorus collectors on the mineral surfaces on the molecular scale. All these theoretical findings, have been reported in the literature, provide indirect evidence about the molecule aggregation behavior and the hydrophobic character of the mineral in the presence of various reagents.

As part of our previous research, potassium cetyl phosphate (PCP) was identified as a promising flotation collector for the selective flotation of magnesite from dolomite and calcite in the presence of sodium silicate [22,23]. Some aspects of the fundamental chemistry issues in magnesite flotation are still considered to be incomplete. To our knowledge, no studies have investigated the microscopic structure and adsorption properties of alkyl phosphate collectors with a long chain on carbonate minerals such as PCP together with the related chemical equilibria in aqueous solution. In this work, a series of microflotation tests, zeta potential and contact angle measurements carried out are highlighted. Moreover, MD simulations that have recently been conducted on adsorption features of PCP on magnesite surfaces are presented as a further contribution to a better understanding of this flotation system.

\section{Materials and Methods}

\subsection{Minerals and Reagents}

The magnesite samples used in this work were gathered from British Columbia, Canada. Representative samples were used for microflotation, contact angle, and zeta potential experiments. Typical pieces were hand-picked, crushed, dry ground, and wet sieved (with deionized water) to $75-150 \mu \mathrm{m}$ size fraction. Particles less than $5 \mu \mathrm{m}$ were used for measurements of zeta potential. A small piece $(1.0 \mathrm{~cm} \times 1.0 \mathrm{~cm})$ of polished magnesite specimens was used for the wettability measurement. The compositions of the magnesite samples are listed in Table 1 . The analysis of purity using a dual carbon-sulphur analyzer also indicated that the purity was up to $98 \%$, which meets the requirements for the following studies.

Table 1. Chemical compositions in the single magnesite samples ( $\mathrm{wt} \%$ ).

\begin{tabular}{ccccc}
\hline $\mathrm{MgO}$ & $\mathrm{CaO}$ & $\mathrm{SiO}_{2}$ & $\mathrm{TFe}$ & $\mathrm{Al}_{2} \mathrm{O}_{3}$ \\
\hline 46.87 & 0.32 & 0.84 & 0.12 & 0.03 \\
\hline
\end{tabular}

The surfactant (PCP) provided by Colonial Chemical Inc. (South Pittsburg, TN, USA) is a long-chain organic-salt that is supplied in white powder form. The $\mathrm{pH}$ level of the slurry was adjusted with analytically pure sodium carbonate $\left(\mathrm{Na}_{2} \mathrm{CO}_{3}\right)$ or hydrochloric acid $(\mathrm{HCl})$. Analytically pure $\mathrm{KCl}$ 
was used as the supporting electrolyte for measurements of zeta potential. Analytically pure sodium hydroxide $(\mathrm{NaOH})$ were used as the titrant. Deionized water was obtained from the water purification system of Smart2Pure3 (Thermo Scientific, Waltham, MA, USA) and used in all experiments.

\section{2. $p K_{a}$ Measurements}

The acid dissociation constant $\left(\mathrm{p} K_{\mathrm{a}}\right)$ was measured by the potentiometric titration method [24,25] using a 916 Ti-Touch titrator (Metrohm, Herisau, Switzerland). The $\mathrm{pH}$ values and added volume $(V)$ of $\mathrm{NaOH}(0.10 \mathrm{~mol} / \mathrm{L})$ were determined during the titration. Then, the $\mathrm{p} K_{\mathrm{a}}$ value was calculated based on the first-derivative method $(\Delta \mathrm{pH} / \Delta V)[26]$.

\subsection{Flotation Experiments}

To study the flotation behavior of magnesite, the microflotation experiments were carried out for individual minerals in a vertical microflotation cell with PCP as the collector. The slurry containing a $1.0 \mathrm{~g}$ magnesite sample $(75-150 \mu \mathrm{m})$ and $70 \mathrm{~mL}$ deionized water was conditioned for $2 \mathrm{~min}$ using a Teflon-coated magnetic bar and magnetic stirrer at a speed of $1100 \mathrm{rpm}$. After that, the pH modifier and PCP collector were introduced in turn with agitation for $2 \mathrm{~min}$. Finally, the flotation tests were initiated and continued for $3 \mathrm{~min}$. The froth products and tailings were filtered, dried, and weighed for calculation of magnesite recovery. Each test was repeated three times, and the average recovery was reported. More detailed information about the general procedure together with a flowsheet can be found in our previous work reported elsewhere [22,23].

\subsection{Molecular Dynamics Simulation}

To investigate the adsorption characteristics of PCP on the surfaces of magnesite, molecular dynamics (MD) computations were carried out using the Materials Studio 2017 software modeling and simulation package (BIOVIA, San Diego, CA, USA) [27]. As reported in the literature, magnesite (1 01 1) surfaces were the perfect cleavage planes of magnesite [16], and these planes were chosen as the dominant cleavage planes for the simulations in the current investigation. Geometry optimizations of the monoanionic structure of PCP (Figure 1a) and the optimized magnesite (1 0101$)$ surface (Figure 1b) were first carried out using the DMol3 and CASTEP module, respectively. The phonon spectrum (Figure 1c) with no imaginary frequency appears in the minus $x$ direction, which proves that the structure of PCP is reasonable. Lattice parameters of the crystal structure of magnesite used in this investigation are presented in Table 2.
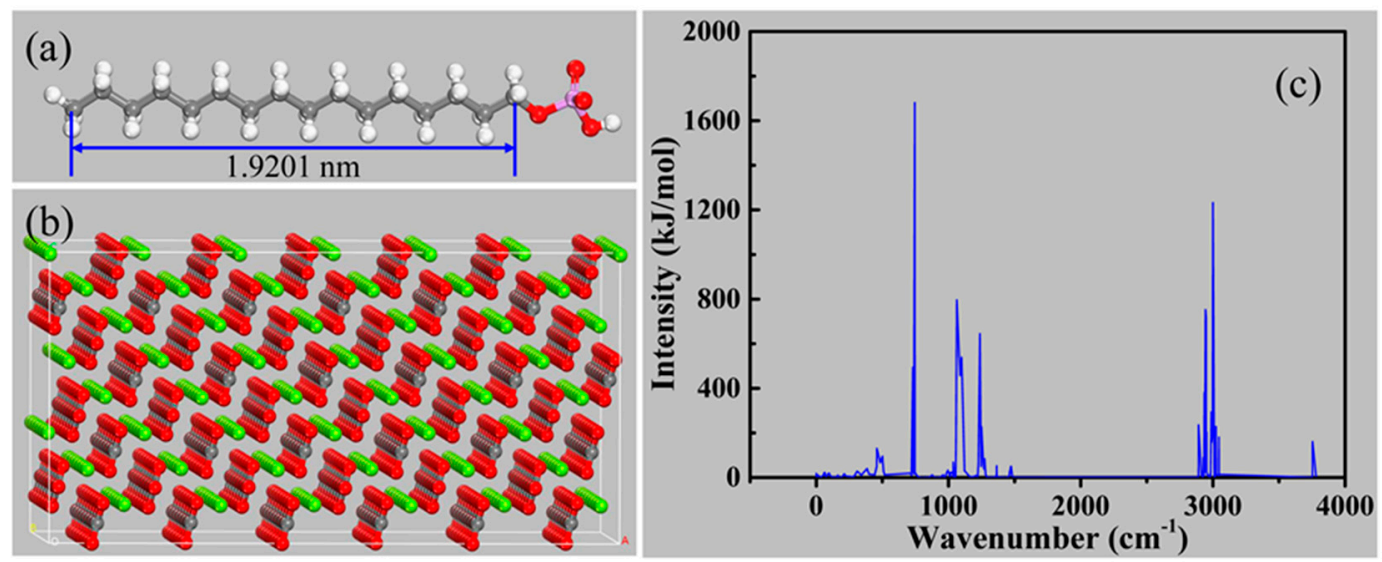

Figure 1. (a) Optimized monoanionic form of potassium cetyl phosphate (PCP); (b) Optimized magnesite $6 \times 7$ supercell; and (c) phonon spectrum of PCP. (Green atoms, Mg; Red atoms, O; White atoms, H; Grey atoms, C; Pink atoms, P). 
Table 2. Lattice parameters of the crystal structure of magnesite.

\begin{tabular}{cccccccc}
\hline Mineral & Values & $\boldsymbol{a}(\mathbf{n m})$ & $\boldsymbol{b}(\mathbf{n m})$ & $\boldsymbol{c}(\mathbf{n m})$ & $\boldsymbol{\alpha}\left({ }^{\circ}\right)$ & $\boldsymbol{\beta}\left(^{\circ}\right)$ & $\gamma\left({ }^{\circ}\right)$ \\
\hline \multirow{2}{*}{ Magnesite } & Experimental $^{1}$ & 0.464 & 0.464 & 1.503 & 90 & 90 & 120 \\
& Optimized $^{\circ}$ & 0.469 & 0.469 & 1.515 & 90 & 90 & 120 \\
\hline
\end{tabular}

${ }^{1}$ Reference [28] for experimental structural data of magnesite.

Each adsorption model consists of three layers: a bottom layer, a middle layer, and a top layer. A $6 \times 7$ magnesite $\left(\begin{array}{lll}1 & 0 & 1\end{array}\right)$ supercell with a size of $3.11 \mathrm{~nm} \times 3.25 \mathrm{~nm} \times 1.57 \mathrm{~nm}(a \times b \times c)$ was built as the bottom layer (see Figure 1b). Furthermore, the reagent solution model composed the medium layer, which was constructed with 1500 water molecules and 20 monoanions of PCP by using the amorphous cell module. Finally, to prevent the migration of surfactant molecules from the solid/liquid interface to the gas/liquid interface, a frozen top layer was constructed from 500 water molecules. To preliminarily optimize the adsorption model, the geometry optimization was conducted using the Forcite Plus module. Moreover, the main parameters in the process include the COMPASS II forcefield [29] and the QEq charge equilibration method [30]. Atom-based and Ewald summation methods were used to calculate the van der Waals force and electrostatic energy, respectively. After initial optimization, MD calculations at NVT [31], NVE [32], and NVT ensembles were performed orderly. Finally, configuration with the lowest energy was chosen as the final adsorption configuration. More details on the application and various aspects of the simulation methodology can be found in the literature [33].

\subsection{Zeta Potential and Wettability Measurements}

In the present investigation, zeta potential measurements of magnesite at different $\mathrm{pH}$ values in the absence and presence of PCP were carried out using a Zeta Potential Finder Analyzer (Matec Applied Science, Northborough, MA, USA) at room temperature.

In addition, the captive bubble contact angle technique was used to assess the variation of wettability of magnesite in the absence and presence of PCP. More information on details of these measurements can be found elsewhere [22,23].

\section{Results and Discussion}

\subsection{Distribution of Species in PCP Solution}

The acid dissociation constant $\mathrm{p} K_{\mathrm{a}}$, as a physicochemical parameter of a reagent, is of fundamental importance in aqueous systems, which may be used in many areas such as mining, chemical as well as pharmaceutical industries [34]. The $\mathrm{p} K_{\mathrm{a}}$ values represent a quantitative property describing the acid-base ionization behavior of chemical substance donating or accepting a proton. The lower the $\mathrm{p} K_{\mathrm{a}}$ value, the stronger the acidic character will be. As a potassium-containing salt, the dissociation equilibria of cetyl phosphate $(\mathrm{CP})$ species determined is shown in Figure 2. Based on the first-derivative method, the experimental $\mathrm{p} K_{\mathrm{a} 1}$ value of $\mathrm{CP}$ is 2.02 , and the $\mathrm{p} K_{\mathrm{a} 2}$ value is 7.49 . Thus, $\mathrm{CP}, \mathrm{CP}^{-}$, and $\mathrm{CP}^{2-}$ are the dominant species in aqueous solutions.

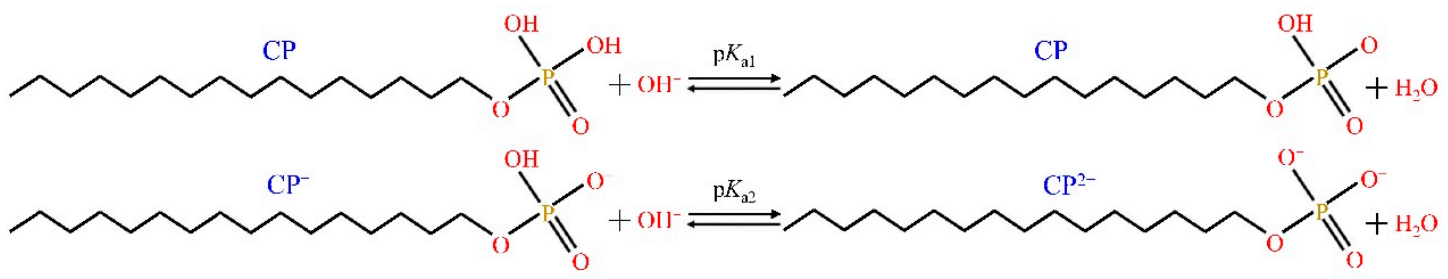

Figure 2. The dissociation equilibrium of cetyl phosphate (CP) species in aqueous solutions.

On the basis of ionization constants obtained, the distribution diagram of $\mathrm{CP}$ species as a function of $\mathrm{pH}$ was calculated, and the results are shown in Figure 3. In strongly acidic conditions (up to a $\mathrm{pH}$ 
of 2), PCP molecules are the dominant species; they tend to disappear at a $\mathrm{pH}$ of about 5.0. $\mathrm{CP}^{-}$species become the dominant species at the $\mathrm{pH}$ range of 2 to 7.5 , and the first dissociation of cetyl phosphate is almost complete at $\mathrm{pH} 10.5$. However, $\mathrm{CP}^{2-}$ appears at $\mathrm{pH} 5$ and tends to dominate solution equilibria as the $\mathrm{pH}$ increases in the alkaline direction. It is the only species beyond $\mathrm{pH} 10$.

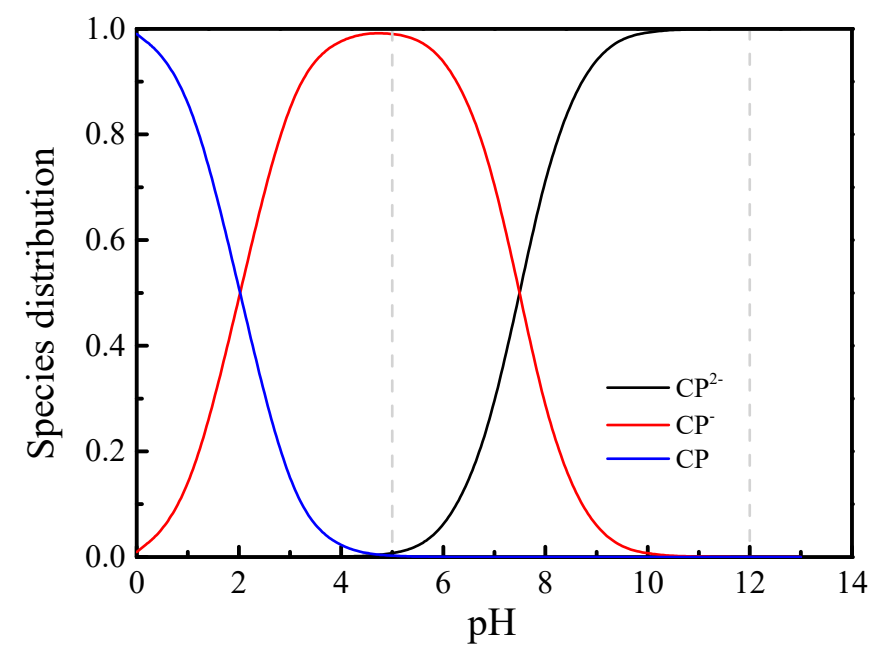

Figure 3. Distribution diagram of $\mathrm{CP}$ species in solution as a function of $\mathrm{pH}$.

Furthermore, magnesite is susceptible to dissolution under acidic conditions. As such, its flotation circuits are maintained in neutral or alkaline $\mathrm{pH}$ range. Thus, in this work, a pH range of 5-12 was selected for the flotation experiments. As a result, the monoanionic and dianionic forms $\left(\mathrm{CP}^{2-}\right.$ and $\mathrm{CP}^{-}$) of PCP are the dominant species within the $\mathrm{pH}$ range investigated in the current work.

\subsection{Distribution of Ionic Species of Magnesite}

Distribution of ionic species in aqueous suspension of the mineral exhibit significant effects on its flotation behavior [13]. The effect of the dissolution behavior on the flotation of salt-type minerals was studied, which showed that solution composition, surface charge, and floatability were crucially affected [35]. Thus, the investigation of solution chemistry is particularly important for carbonate minerals. In this work, the equations of ionic equilibrium in $\mathrm{MgCO}_{3}-\mathrm{H}_{2} \mathrm{O}-\mathrm{CO}_{2}(\mathrm{~g})$ open system are shown as follows:

$$
\begin{array}{ll}
\mathrm{MgCO}_{3(\mathrm{~s})} \rightleftharpoons \mathrm{MgCO}_{3(\mathrm{aq})^{-}} & K_{1}=10^{-4.51} \\
\mathrm{Mg}^{2+}+\mathrm{CO}_{3}{ }^{2-} \rightleftharpoons \mathrm{MgCO}_{3(\mathrm{aq})} & K_{2}=10^{3.40} \\
\mathrm{Mg}^{2+}+\mathrm{HCO}_{3}{ }^{-} \rightleftharpoons \mathrm{MgHCO}_{3}{ }^{+} & K_{3}=10^{1.16} \\
\mathrm{Mg}^{2+}+\mathrm{OH}^{-} \rightleftharpoons \mathrm{MgOH}^{+} & K_{4}=10^{2.58} \\
\mathrm{MgOH}^{+}+\mathrm{OH}^{-} \rightleftharpoons \mathrm{Mg}(\mathrm{OH})_{2(\mathrm{aq})} & K_{5}=10^{5.81} \\
\mathrm{Mg}(\mathrm{OH})_{2(\mathrm{~s})} \rightleftharpoons \mathrm{Mg}(\mathrm{OH})_{2(\mathrm{aq})} & K_{6}=10^{-2.67} \\
\mathrm{H}^{+}+\mathrm{CO}_{3}{ }^{2-} \rightleftharpoons \mathrm{HCO}_{3} & K_{7}=10^{10.33} \\
\mathrm{H}^{+}+\mathrm{HCO}_{3}{ }^{-} \rightleftharpoons \mathrm{H}_{2} \mathrm{CO}_{3} & K_{8}=10^{6.35} \\
\mathrm{H}_{2} \mathrm{CO}_{3} \rightleftharpoons \mathrm{CO}_{2}(\mathrm{~g})+\mathrm{H}_{2} \mathrm{O} & K_{9}=10^{1.47}
\end{array}
$$

As a sparingly soluble mineral, the hydration and dissolution of lattice ions tend to equilibrate in time after magnesite is immersed in aqueous media [35]. Calculations of the solution chemistry based on Equilibria (1)-(9) [13,36] were conducted as a function of $\mathrm{pH}$, and the results are shown in Figure 4. As can be noted, the magnesium species in the aqueous environment including $\mathrm{Mg}^{2+}$, $\mathrm{MgOH}^{+}, \mathrm{MgHCO}_{3}{ }^{+}, \mathrm{MgCO}_{3(\mathrm{aq})}$, and $\mathrm{Mg}(\mathrm{OH})_{2(\mathrm{aq})}$ vary widely in concentration profiles with respect 
to $\mathrm{pH}$. The concentration of $\left[\mathrm{Mg}^{2+}\right]$ species decreases with increasing $\mathrm{pH}$ values. However, it is the dominant magnesium species below the $\mathrm{pH}$ of 9.3. Moreover, the results suggest that most of the dissolved carbonate was converted to $\mathrm{Mg}(\mathrm{OH})_{2(\mathrm{aq})}$ at $\mathrm{pH}>10$. The modification of surface properties of magnesite is induced by the conversion of magnesium species into a variety of ionic forms. Results are in agreement with previously reported findings [13]. It is clear that the ionic species concentrations of dissolved magnesite in aqueous suspension are controllable by adjusting the pH of the slurry. It can be noted that the development of surface charges (hence, zeta potentials) of magnesite can be predicted based on the chemical equilibria in Figure 4. It can be noted that isoelectric point (IEP) value for magnesite, depending on $\mathrm{Mg}^{2+}$ and $\mathrm{CO}_{2}$ equilibrium, can occur in the weakly alkaline $\mathrm{pH}$ range, where the concentration lines representing positively and negatively charged ions cross. These are in line with zeta potential results as will be discussed later. Magnesite was negatively charged in the $\mathrm{pH}$ range of 7.0-12.0 while it was positively charged in the $\mathrm{pH}$ range of 5.0-7.0. These results are in general agreement with the IEP range reported by Pokrovsky [37].

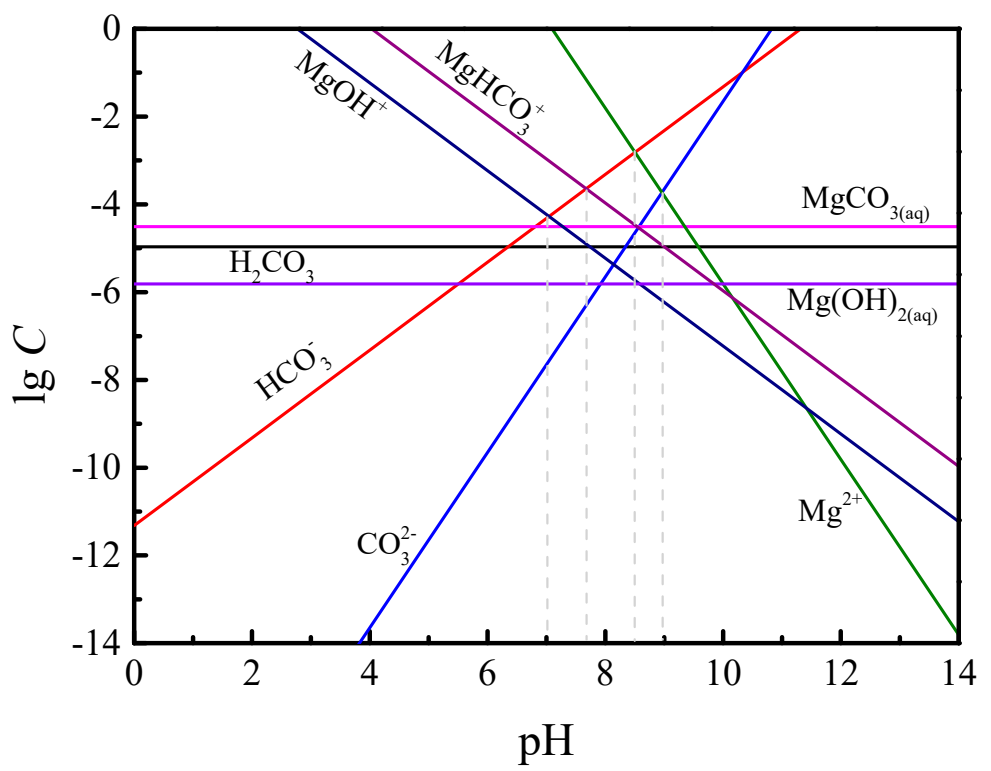

Figure 4. Distribution diagram of ionic species in aqueous suspension of magnesite open to atmospheric carbon dioxide.

\subsection{Microflotation Results}

The results of the effect of PCP concentration and $\mathrm{pH}$ level on the flotation behavior of magnesite are presented in Figure 5. The natural $\mathrm{pH}$ value is about 6.8 for magnesite slurry. It can be seen that the flotation recovery of magnesite increases with increasing PCP concentration from 20 to $240 \mathrm{mg} / \mathrm{L}$. Moreover, as the $\mathrm{pH}$ level increases from approximately 7.0 to 11.0 , changes of the magnesite recovery are not obvious at the same PCP concentration. Thus, the recovery curve is rather flat with respect to the slurry $\mathrm{pH}$. When $60 \mathrm{mg} / \mathrm{L} \mathrm{PCP}$ was used, the recovery of magnesite at $\mathrm{pH} 7.0,9.1$, and 11.0 reached a high level of $93.0 \%, 95.8 \%$, and $93.8 \%$, respectively. The results indicated that the PCP collector exhibited a strong collecting ability for magnesite at low PCP concentrations. Therefore, the optimum pH of approximately 7.0 and PCP with a concentration of $60 \mathrm{mg} / \mathrm{L}$ was chosen for the subsequent tests. 


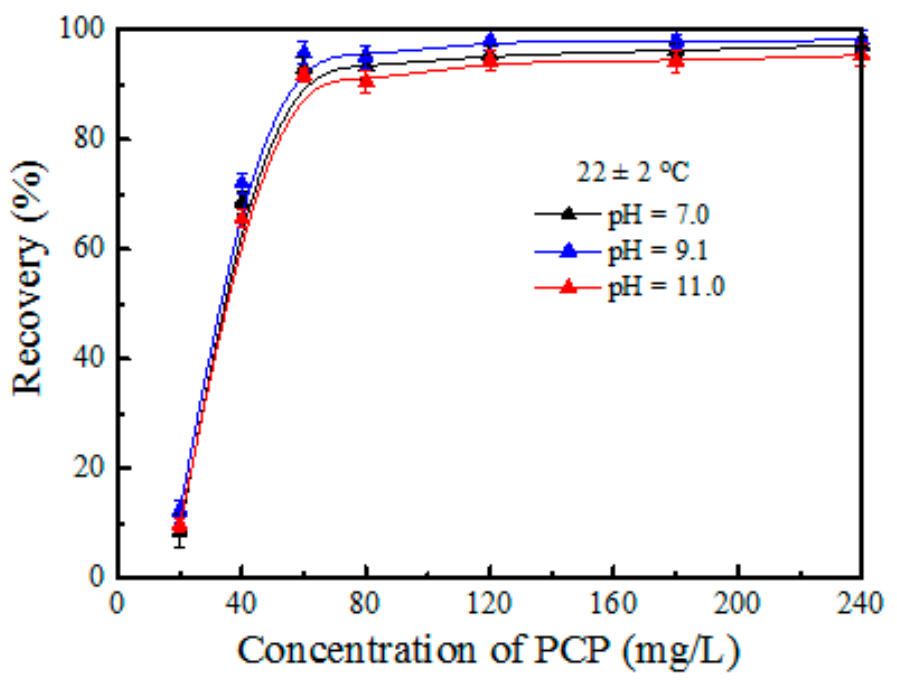

Figure 5. Flotation behaviors of magnesite as a function of PCP concentration at different $\mathrm{pH}$ levels.

\subsection{Electrokinetic Behavior and Wettability}

The zeta potential behavior of magnesite as a function of $\mathrm{pH}$ is highlighted in Figure 6 . The zeta potentials decreased when the $\mathrm{pH}$ increased. In the absence of $\mathrm{PCP}$, the isoelectric point value of magnesite is approximately pH 7.3 [22,23]. As discussed in Section 3.2, this value is in a pH range predictable according to chemical equilibria, and is in agreement with the range reported previously [37]. After conditioning in the $60 \mathrm{mg} / \mathrm{L}$ PCP solution, the zeta potentials showed a remarkable shift in the negative direction. Moreover, the changes significantly increased within the pH range from 5 to 11 , which can be attributable to the strong adsorption of PCP on the magnesite surface in this range. Through an additional evidence obtained from XPS analysis, it can be concluded that this adsorption is of a chemical nature [22].

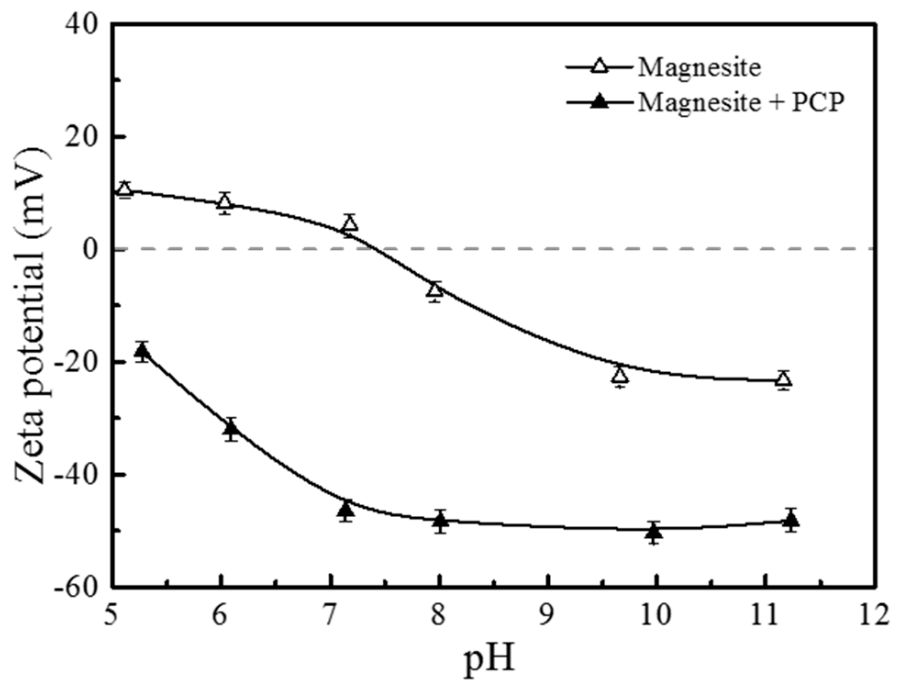

Figure 6. Zeta potentials of magnesite as a function of $\mathrm{pH}$ without and with $60 \mathrm{mg} / \mathrm{L} \mathrm{PCP}$.

Table 3 highlights the wettability changes brought about by adsorption of PCP on magnesite at a concentration of $60 \mathrm{mg} / \mathrm{L}$. In the absence of PCP, the contact angle of magnesite, as expected, has been zero over the $\mathrm{pH}$ range studied confirming its natural hydrophilicity [38]. However, when treated with $60 \mathrm{mg} / \mathrm{L} \mathrm{PCP}$, the contact angles of magnesite increased significantly to values between 41.5 to 37.2 degrees as the $\mathrm{pH}$ increased. 
Table 3. Contact angles of magnesite without and with $60 \mathrm{mg} / \mathrm{L} \mathrm{PCP}\left(^{\circ}\right)$.

\begin{tabular}{cccc}
\hline Samples & pH 7.0 & pH 9.0 & pH 11.0 \\
\hline Magnesite & $0^{1}$ & 0 & 0 \\
Magnesite + PCP & 41.5 & 39.9 & 37.2 \\
\hline${ }^{1}$ Contact angle of zero means no bubbles were captured.
\end{tabular}

Thus, the adsorption of PCP on the magnesite surface not only caused a significant alteration in the electrical double layer of magnesite but also in its surface energy level. The adsorption of PCP changed the magnesite surface from its naturally high surface energy state to a low energy state that was accompanied by the development of hydrophobicity, which was sufficient for its flotation. These findings on electrokinetics and wettability correlate well with the flotation results discussed earlier.

\subsection{Molecular Modeling Studies}

\subsubsection{Adsorption Characteristics of CP Species}

MD simulations were undertaken to investigate the adsorption behavior of cetyl phosphate (CP) species on the magnesite surfaces from a theoretical point of view [33]. The optimum flotation parameters discussed earlier included a $\mathrm{pH}$ value of 7.0 and $60 \mathrm{mg} / \mathrm{L} \mathrm{PCP}$, where the monoanionic forms of $\mathrm{CP}^{-}$are the dominant species in solution at a $\mathrm{CP}^{-} / \mathrm{CP}^{2-}$ ratio greater than 2 . Thus, the optimized monoanionic forms of $\mathrm{CP}^{-}$(Figure 1a) were used in the simulation. The representation of the initial simulation model and the interaction model of magnesite after $\mathrm{CP}^{-}$adsorption are shown in Figure 7 . Compared to the adsorption models, $\mathrm{CP}^{-}$ions were randomly distributed before interacting with magnesite surfaces. With an increase in the simulation time, the surfactant molecules adsorbed on magnesite surfaces and formed a surfactant layer via orientation of the non-polar cetyl chains and ionizable polar heads, $-\mathrm{PO}_{4} \mathrm{H}_{2}$. After a series of $\mathrm{MD}$ simulations, the cetyl monoanionic species were markedly moved down with the polar heads to the surface of magnesite. The non-polar cetyl chains of $\mathrm{CP}^{-}$are directed towards the air/liquid interface, a favorable orientation inducing hydrophobicity for bubble contact. This sub-process requires depletion of water molecules at the interface, thereby imparting a sufficiently high level of hydrophobicity to the magnesite surface following the adsorption of $\mathrm{CP}^{-}$.

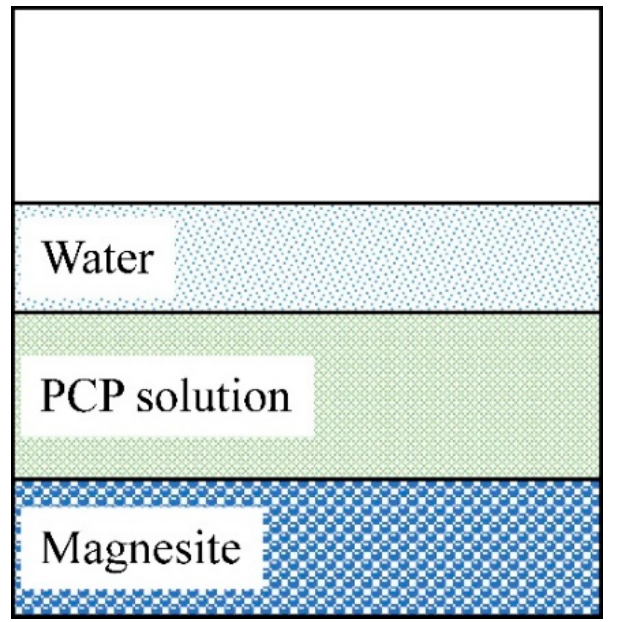

(a)

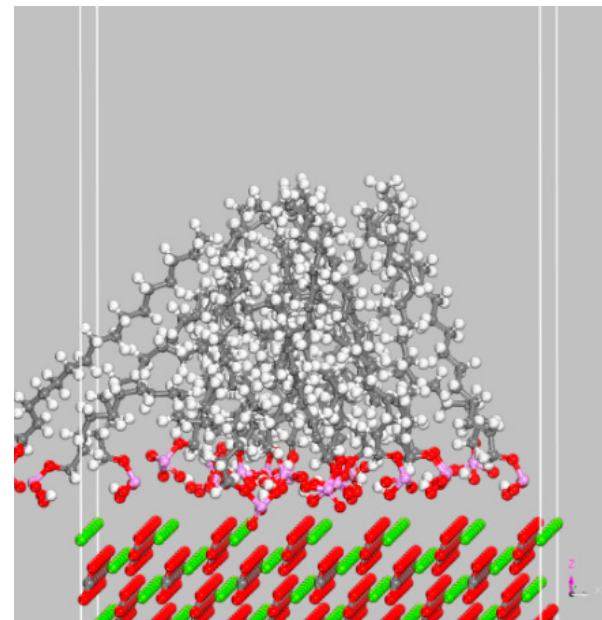

(b)

Figure 7. (a) Representation of the initial simulation model; (b) Molecular model of the magnesite (1 $\left.\begin{array}{lll}1 & 1\end{array}\right)$ surface after $\mathrm{CP}^{-}$adsorption (Water molecules were invisible). 
In order to further understand the microspatial structure of $\mathrm{CP}^{-}$at the interfaces, the length of the hydrocarbon chain (distances between the head and tail carbon atoms) in $\mathrm{CP}^{-}$was selected for statistical analysis. The results of the probability density are shown as a function of the length of the hydrocarbon chain in Figure 8. It can be seen that the distance distribution between the head and tail carbon atoms in $\mathrm{CP}^{-}$is mainly distributed in the range of 1.6-1.9 nm compared to that in the initial structure (1.9201 nm, see Figure 1a). Thus, the $\mathrm{CP}^{-}$molecules on the solid/liquid interface are affected by two factors, one is the effect of water molecules in the solution, and the other one is the attraction surface forces, which result in apparent steric effects. Water molecules hinder the migration of $\mathrm{CP}^{-}$ from the liquid phase to the gas phase. Thus, the $\mathrm{CP}^{-}$ions are fixed at the solid/liquid interface without freely stretching of hydrocarbon chains to the gas/liquid interface.

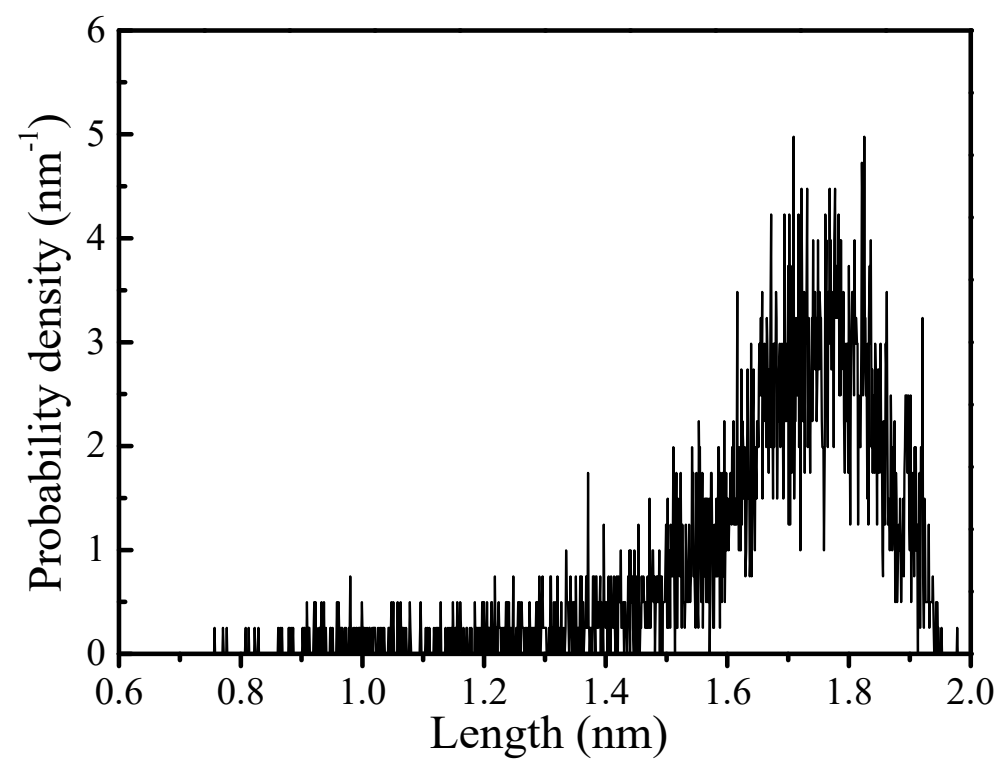

Figure 8. Length distribution of the hydrocarbon chain in $\mathrm{CP}^{-}$on the magnesite surface.

\subsubsection{Relative Density Distribution and Density Field}

To further explore the $\mathrm{CP}^{-}$adsorption, the relative density distribution analysis was conducted to quantify the distribution of collector on magnesite surfaces. Figure 9a shows the relative concentrations of $\mathrm{O}, \mathrm{P}$, and $\mathrm{C}$ atoms and cetyl phosphate on the magnesite surface as a function of distance (along the $z$-axis). The location of the first peak of $\mathrm{O}$ atoms for $\mathrm{CP}$ was found at $0.21 \mathrm{~nm}$ away from the magnesite surface, compared to that of $P$ atoms at $0.32 \mathrm{~nm}$, and that of $\mathrm{C}$ atoms at $0.63 \mathrm{~nm}$. Since $\mathrm{O}$ atoms are the closest to the magnesite surface, they are deduced to be the primary bonding atoms in $\mathrm{CP}^{-}$. Moreover, the adsorbed $\mathrm{CP}^{-}$ions as a whole are distributed at an approximate distance of $0.2-2.5 \mathrm{~nm}$. Based on the analysis of a similar magnesite flotation system, the nearest $\mathrm{CP}^{-}$ions can be inferred to chemically bond at an approximately $0.2 \mathrm{~nm}$ distance away from the magnesite surface [16]. According to the current results, the hydrophobic layer of $\mathrm{CP}^{-}$extends into a distance of $2.3 \mathrm{~nm}$ from the magnesite surface. Figure $9 \mathrm{~b}$ showed results of the density field of $\mathrm{O}$ atoms in $\mathrm{CP}^{-}$, which also illustrates the distribution of $\mathrm{CP}^{-}$. As can be noted, the $\mathrm{O}$ atoms are mainly concentrated near the magnesite surface, correlating well with the adsorption configuration shown earlier. In this work, it appears that the surface magnesium with collector oxygen is the primary bond, which is believed to form a covalent bond through chemisorption [39]. 


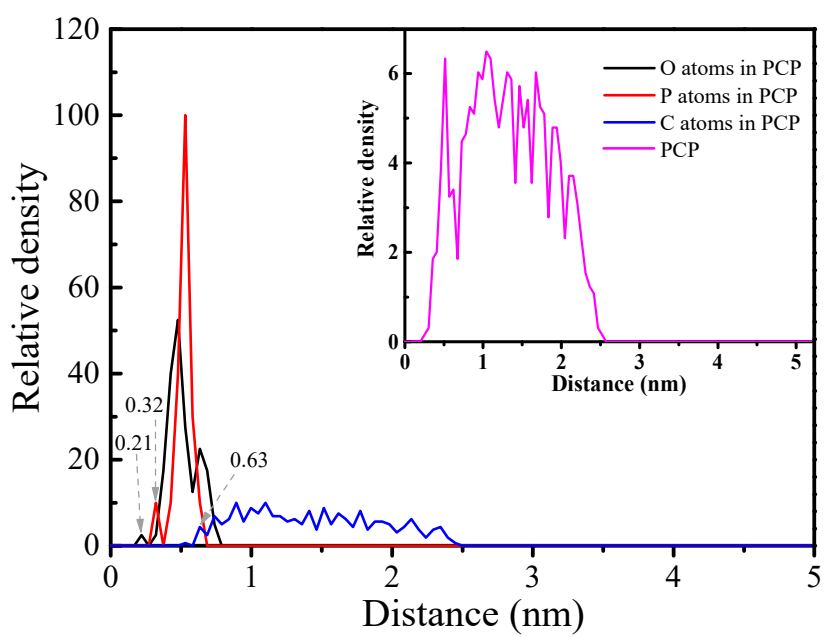

(a)

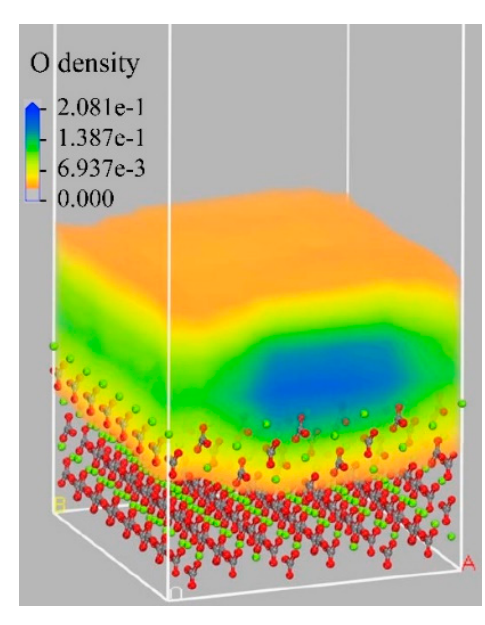

(b)

Figure 9. (a) Relative density distribution of the $\mathrm{O}, \mathrm{P}$, and $\mathrm{C}$ atoms of the $\mathrm{CP}^{-}$adsorbed and $\mathrm{CP}^{-}$on the magnesite surface as a whole; (b) Density field of $\mathrm{O}$ atoms on the magnesite surface.

\section{Summary and Conclusions}

The results of flotation response issues of magnesite in the presence of potassium cetyl phosphate (PCP) as a new collector were presented, which summarized floatability, hydrophobicity/wettability, and electrokinetic behavior. The adsorption phenomenon of $\mathrm{CP}^{-}$and the interaction mechanism were discussed based on the theoretical analysis of solution chemistry and molecular dynamics simulation. Conclusions at this time include the following points:

1. Based on the results of flotation experiments, it is clear that PCP is a promising collector for magnesite with excellent recoveries even at a low concentration $(60 \mathrm{mg} / \mathrm{L})$.

2. Results from chemical computations confirmed that the monoanionic forms of $\mathrm{CP}$ are the dominant species within the $\mathrm{pH}$ range used in this study. The measured isoelectric point of magnesite was $\mathrm{pH}$ 7.3, which is the $\mathrm{pH}$ range predictable from the analysis of chemical equilibria diagrams (7.0).

3. The adsorption of $\mathrm{CP}^{-}$on the magnesite surface causes significant negative shifts in the zeta potentials and results in the development of a significant level of hydrophobicity on magnesite. It is more likely that the reason for these results is the strong and stable interactions between the magnesite surface and $\mathrm{CP}$ species.

4. According to the simulations, the $\mathrm{O}$ atoms in the polar phosphate head group are the primary bonding atoms, which explains the floatability of magnesite with $\mathrm{CP}$. The chemisorption of $\mathrm{CP}$ was supported by a large concentration of adsorbed species in the immediate vicinity of the magnesite surface, with the expected orientation of cetyl groups towards the bulk solution and hence the air-solution interface.

Author Contributions: Conceptualization, Y.T. and S.K.; methodology, Y.T.; software, Y.T., J.Y. and W.Y.; validation, S.K., W.Y. and Y.T.; formal analysis, J.Y. and S.K.; investigation, Y.T.; writing —original draft preparation, Y.T.; writing-review and editing, S.K.; supervision, S.K. and W.Y. All authors have read and agreed to the published version of the manuscript.

Funding: This research was funded by the National Natural Science Foundation of China, grant number 51874072 and 51974064, and Yuan's fellowship was provided by the China Scholarship Council, grant number 201806080082. Some of the research expenses have been covered through a discovery grant from NSERC.

Acknowledgments: Larissa Smith, the mineral processing technician in the Robert M. Buchan Department of Mining at Queen's is thanked for her availability, whenever needed in the research labs.

Conflicts of Interest: The authors declare no conflict of interest. 


\section{References}

1. Yin, W.Z.; Tang, Y. Interactive effect of minerals on complex ore flotation: A brief review. Int. J. Miner. Metall. Mater. 2020, 27, 571-583. [CrossRef]

2. Yao, J.; Yin, W.Z.; Gong, E.P. Depressing effect of fine hydrophilic particles on magnesite reverse flotation. Int. J. Miner. Process. 2016, 149, 84-93. [CrossRef]

3. Chen, G.; Tao, D. Reverse flotation of magnesite by dodecyl phosphate from dolomite in the presence of sodium silicate. Sep. Sci. Technol. 2004, 39, 377-390. [CrossRef]

4. Doerner, H.A.; Dwight, L. Concentration of low-grade magnesite ores by flotation. US Bur. Mines Bull. 1938, 1, 1-30.

5. Matis, K.A.; Gallios, G.P. Anionic flotation of magnesium carbonates by modifiers. Int. J. Miner. Process. 1989, 25, 261-274. [CrossRef]

6. Sahoo, H.; Sinha, N.; Rath, S.S.; Das, B. Ionic liquids as novel quartz collectors: Insights from experiments and theory. Chem. Eng. J. 2015, 273, 46-54. [CrossRef]

7. Huang, Z.Q.; Zhong, H.; Wang, S.; Xia, L.; Zou, W.; Liu, G. Investigations on reverse cationic flotation of iron ore by using a Gemini surfactant: Ethane-1,2-bis(dimethyl-dodecyl- ammonium bromide). Chem. Eng. J. 2014, 257, 218-228. [CrossRef]

8. Florek, I. The effects of radiation pretreatment on the floatability of magnesite and siderite. Miner. Eng. 1995, 8, 329-331. [CrossRef]

9. Brando, P.R.G.; Poling, G.W. Anionic flotation of magnesite. Can. Metall. Q. 1982, 3, 211-220. [CrossRef]

10. Wonyen, D.; Kromah, V.; Gibson, B.; Nah, S.; Chelgani, S.A. Review of flotation separation of Mg carbonates (Dolomite and Magnesite). Minerals 2018, 8, 354. [CrossRef]

11. Liu, W.; McDonald IV, L.W.; Wang, X.; Miller, J.D. Bastnaesite flotation chemistry issues associated with alkyl phosphate collectors. Miner. Eng. 2018, 127, 286-295. [CrossRef]

12. Li, F.; Zhong, H.; Zhao, G.; Wang, S.; Liu, G. Flotation performances and adsorption mechanism of $\alpha$-hydroxyoctyl phosphinic acid to cassiterite. Appl. Surf. Sci. 2015, 353, 856-864. [CrossRef]

13. Chen, G.; Tao, D. Effect of solution chemistry on flotability of magnesite and dolomite. Int. J. Miner. Process. 2004, 74, 343-357. [CrossRef]

14. Zhou, G.; Luo, J. Mechanism of flotation using citric acid for separating monazite from bastnaesite. Nonferrous Met. 1989, 41, 33-40.

15. Zhou, G.; Luo, J. Mechanism of flotation using mono-alkyl ester phosphoric acid for bastnaesite. J. Chin. Rare Earth Soc. 1990, 8, 261-264.

16. Zhang, H.; Liu, W.; Han, C.; Hao, H. Effects of monohydric alcohols on the flotation of magnesite and dolomite by sodium oleate. J. Mol. Liq. 2018, 249, 1060-1067. [CrossRef]

17. Paschek, D.; Engels, T.; Geiger, A.; von Rybinski, W. MD-simulation study of the hydrophobic hydration of nonionic surfactants. Colloids Surf. A 1999, 489-500. [CrossRef]

18. de Leeuw, N.H.; Cooper, T.G. A computational study of the surface structure and reactivity of calcium fluoride. J. Mater. Chem. 2003, 13, 93-101. [CrossRef]

19. Yin, X.; Miller, J.D. Wettability of kaolinite basal planes based on surface force measurements using atomic force microscopy. Min. Metall. Explor. 2012, 29, 13-19. [CrossRef]

20. Domínguez, H. Self-aggregation of the SDS surfactant at a solid-liquid interface. J. Phys. Chem. B 2007, 111, 4054-4059. [CrossRef]

21. Zhang, H.; Liu, W.; Han, C.; Wei, D. Intensify dodecylamine adsorption on magnesite and dolomite surfaces by monohydric alcohols. Appl. Surf. Sci. 2018, 444, 729-738. [CrossRef]

22. Tang, Y.; Yin, W.; Kelebek, S. Magnesite-dolomite separation using potassium cetyl phosphate as a novel flotation collector and related surface chemistry. Appl. Surf. Sci. 2020, 508, 145191. [CrossRef]

23. Tang, Y.; Yin, W.; Kelebek, S. Selective flotation of magnesite from calcite using potassium cetyl phosphate as a collector in the presence of sodium silicate. Miner. Eng. 2020, 146, 106154. [CrossRef]

24. Reijenga, J.; van Hoof, A.; van Loon, A.; Teunissen, B. Development of methods for the determination of $\mathrm{pKa}$ values. Anal. Chem. Insights. 2013, 8, 53-71. [CrossRef] [PubMed]

25. Avdeef, A.; Comer, J.E.A.; Thomson, S.J. pH-Metric log P. 3. glass electrode calibration in methanol-water, Applied to $\mathrm{p} K_{\mathrm{a}}$ determination of water-insoluble substances. Anal. Chem. 1993, 65, 42-49. [CrossRef] 
26. Qiang, Z.; Adams, C. Potentiometric determination of acid dissociation constants ( $\mathrm{p} K_{\mathrm{a}}$ ) for human and veterinary antibiotics. Water Res. 2004, 38, 2874-2890. [CrossRef]

27. BIOVIA Materials Studio 2017 (17.1.0.48). Available online: http://accelrys.com/products/collaborativescience/biovia-materials-studio/ (accessed on 12 April 2020).

28. Maslen, E.N.; Streltsov, V.A.; Streltsova, N.R. X-ray study of the electron density in magnesite $\mathrm{MgCO}_{3}$. Acta Cryst. B 1993, 49, 980-984. [CrossRef]

29. Sun, H.; Jin, Z.; Yang, C.; Akkermans, R.L.; Robertson, S.H.; Spenley, N.A.; Miller, S.; Todd, S.M. COMPASS II: Extended coverage for polymer and drug-like molecule databases. J. Mol. Model. 2016, 22, 1-10. [CrossRef]

30. Kitao, O.; Miura, N.; Ushiyama, H. Molecular mechanics with QEq-CS (charge equilibration method generalized for charge separation system). J. Mol. Struct. THEOCHEM 1999, 461, 239-247. [CrossRef]

31. Labík, S.; Smith, W.R. Scaled particle theory and the efficient calculation of the chemical potential of hard spheres in the NVT ensemble. Mol. Simul. 1994, 12, 23-31. [CrossRef]

32. Kraska, T. Molecular-dynamics simulation of argon nucleation from supersaturated vapor in the NVE ensemble. J. Chem. Phys. 2006, 124, 054507. [CrossRef] [PubMed]

33. Tang, Y.; Kelebek, S.; Yin, W. Surface chemistry of magnesite and calcite flotation and molecular dynamics simulation of their cetyl phosphate adsorption. Colloids Surf. A 2020, 603, 125246. [CrossRef]

34. Babić, S.; Horvat, A.J.; Pavlović, D.M.; Kaštelan-Macan, M. Determination of pKa values of active pharmaceutical ingredients. Trends Anal. Chem. 2007, 26, 1043-1061. [CrossRef]

35. Hu, Y.H. Research on Solution Chemistry and Flotability of Salt-Type Minerals. Ph.D. Thesis, Central South University, Changsha, China, 1989.

36. Wang, D.Z.; Hu, Y.H. Solution Chemistry of Flotation; Hunan Science and Technology Press: Beijing, China, 1988; pp. 235-238.

37. Pokrovsky, O.S.; Schott, J.; Thomas, F.; Mielczarski, J. Surface speciation of Ca and Mg carbonate minerals in aqueous solutions: A combined potentiometric, electrokinetic, and DRIFT surface spectroscopy approach. Mineral. Mag. 1998, 62, 1196-1197. [CrossRef]

38. Gence, N. Wetting behavior of magnesite and dolomite surfaces. Appl. Surf. Sci. 2006, 252, 3744-3750. [CrossRef]

39. Spiritu, E.R.L.; Naseri, S.; Waters, K.E. Surface chemistry and flotation behavior of dolomite, monazite and bastnäsite in the presence of benzohydroxamate, sodium oleate and phosphoric acid ester collectors. Colloids Surf. A 2018, 546, 254-265. [CrossRef]

(C) 2020 by the authors. Licensee MDPI, Basel, Switzerland. This article is an open access article distributed under the terms and conditions of the Creative Commons Attribution (CC BY) license (http://creativecommons.org/licenses/by/4.0/). 